ISSN: 0377-6395
e-ISSN: 2651-4214
JOURNAL OF TURKISH VETERINARY MEDICAL SOCIETY
Dergi ana sayfasi:
Journal homepage:
http://dergipark.org.tr/vetheder

DOI: $10.33188 /$ vetheder.494535

Olgu Sunumu / Case Report

\title{
İki köpekte kısa radius sendromunun sağaltımı
}

\author{
Sinan ULUSAN ${ }^{1, a^{*}, \ddot{O}_{z g e} \text { ÇAPTUĞ ÖZDEMİR }}{ }^{2, b}$, Hasan BILLGiLI $\dot{I}^{3, c}$ \\ ${ }^{1}$ Balıkesir Üniversitesi Veteriner Fakültesi Cerrahi Anabilim Dall, Ballkesir,Türkiye \\ ${ }^{2}$ Cumhuriyet Üniversitesi Veteriner Fakültesi Cerrahi Anabilim Dal, Sivas, Türkiye \\ ${ }^{3}$ Ankara Üniversitesi Veteriner Fakültesi Cerrahi Anabilim Dall,Ankara, Türkiye \\ ORCID: 0000-0003-0988-4415 a ;0000-0002-2264-5294 ${ }^{\text {b }}$;0000-0003-0090-7000 c
}

\begin{abstract}
MAKALE BiLGISI /
ARTICLE

INFORMATION:

Geliş / Received:

10 Aralı 18

10 December 18

Kabul / Accepted:

16 Mayıs 19

16 May 19
\end{abstract}

Anahtar Sözcükler:

Dirsek displazisi,

Dirsek uyumsuzluğu,

Eksternal skeletal

fiksatör,

Kısa radius sendromu,

Köpek.

Keywords:

Dog,

Elbow dysplasia,

Elbow incoungrity,

External skeletal fixator,

Short radius syndrome.
ÖZET:

$\mathrm{Bu}$ araştırmanın amacı 2 köpekte karşılaşılan kısa Radius sendromunu ve sağaltımı meslektaşlarımızla paylaşmaktır. Köpeklerde dirsek eklemi küçük bir alanda barındırdığı çok sayıda yapı ve kompleks hastalıkları sebebiye önem arz etmektedir. Dirsek radis, ulna ve humerus beraber oluşturdukları, dar bir eklem boşluğuna sahip bir eklemdir. Dirsek ekleminin ortopedik hastalıklarının başında dirsek diplazisi yatmaktadır. Dirsek displazisi birçok hastalığa verilen genel bir isimdir ve bu hastalıkların temelinde yatan en büyük problem dirsek uyumsuzluğudur. Dirsek ekleminin radio ulnar eklem yüzeyini radius ve ulna beraber oluştururlar. Beraber senkronize uzayan bu iki kemik arasında büyümede meydana gelen asenkronizasyon sonucunda dirsek ekleminde çeşitli seviyelerde uyumsuzluk meydana gelir. Kısa radius sendromu köpeklerde nadiren gözlenir ve erken sağalıımı önem taşımaktadır. Kaput radiinin kısalığı dirsekte mediyal koronoid prossesin kırık ve lezyonlarına yol açmaktadır. Bu çalışmada 2 köpekte karşılaşılan kısa radius sendromuna bağlı dirsek uyumusuzluğunun, kirschner teli ve elastik bant yöntemi ile sağaltımı konu edilmiştir. Hastalarda sağaltım başarı ile tamamlanmış ve uyumsuzluk giderilmiştir.

\section{Treatment of short radius syndrome in two dogs}

ABSTRACT:

The aim of this study is to share the short radius syndrome that encountered in 2 dogs and its treatment with our colleagues. The elbow joints in dogs are important because of having many structures in a small joint and their complex diseases. The elbow is a joint with a narrow joint space formed by the radius, ulna and humerus. Elbow dysplasia is the main problem of elbow joint. Elbow dysplasia is a general name given to many diseases and the biggest problem underlying these diseases is elbow incongruity. Radius and ulna form the radio-ulnar joint surface of the elbow together. Growth dissynchronisation in those two bones which have synchronised growth, result with various incompatibility in elbow joint. Short radius syndrome is rarely seen in dogs and early treatment is important. The shortness of the caput radii leads to fractures and lesions of the medial coronoid process. In this study, the treatment of elbow incongruity due to short radius syndrome encountered in 2 dogs by Kirschner wire and elastic band method are discussed. Treatment was completed successfully and incongruity was corrected.

How to cite this article: Ulusan S, Özdemir ÖÇ, Bilgili H:. İki köpekte kısa radius sendromunun sağaltımı. Vet Hekim Der Derg, 90 (2): 158-163, 2019. DOI: $10.33188 /$ vetheder.494535

* Sorumlu yazar/Corresponding author

eposta adresi/e-mail address: sinanulusan@hotmail.com 


\section{Giriş}

Köpeklerde dirsek uyumsuzluğu (DU); genetik faktörler, travma, yanlış besleme gibi çeşitli sebeplerden ötürü gelişebilmektedir. DU; birçok yazara göre dirsek displazisi gibi kompleks hastalıkların altında yatan temel sebeptir. Radius, ulna gibi beraber uzamak ve uyumlu eklem yüzü oluşturmak zorunda olan kemiklerin büyümesinde meydana gelen milimetrik sapmalar eklemlerde çeşitli derecede uyumsuzluk ve bunların sonucu bazı hastalıklar meydana getirirler $(2,4,8)$.

Küçük hayvanlarda teşhis edilen ve korrektif osteotomi ile düzeltilen büyüme deformiteleri en yaygın olarak radiusdistal ve ulna'nın büyüme plaklarının erken kapanmasına bağlı olarak şekillenmektedir. Büyüme çağında ulnanın gelişiminin \%85'inden ulnanın distal epifizi sorumlu iken, radius'un gelişiminden $\% 60$ distal ve \%40 radiusun proksimal epifizi sorumludur. Köpek ırklarına göre değişmekle birlikte epifiz hatlarının kapanma yaşları da farklılık göstermektedir. Tüm bu etkenlere rağmen normal bir duruş ve düzgün bir ekstremite için radius ve ulna senkronize olarak gelişmek zorundadır $(1,5)$.

En yaygın olarak görünen büyüme deformitesi ulnanın distal büyüme plăğ’nın erken kapanması sonucu ulna kısalığına bağlı olarak radius'ta kısalma, kraniyal yönde kavislenme, valgus angulasyonu ve eksternal rotasyon şekillemesidir $(1,5)$.

Daha seyrek olarak görünen radiusun proksimal ve distal epifiz kapanmalarından her ikisinin de simetrik olarak kapanması radius kısalığ1 ve humeroradial eklemde subluksasyonuna neden olurken; radiusun distal epifizin asimetrik olarak kapanması kisalmaya ek olarak veya bunun yerine radius'un anguler deformitesine ve humeroradial eklem luksasyonuna neden olur. Radiusun proksimal epifizin erken kapanması çok görülmemekle birlikte şekillendiğinde az miktarda radius kısalığı ile birlikte humeroradial eklemde subluksasyona ve eklemin biyomekanik yük dağılımında çeşitli bozukluklara neden olmaktadır. Radius'un büyüme plaklarının erken kapandığı durumlarda uzamaya devam eden ulna her üç durumda da kaput radiinin distal luksasyonu ve/veya proksimal humeroulnar subluksasyona neden olur buna yazarlar kısa radius sendromu demektedir $(1,3,5)$. Dirsek ekleminde ulnanın mediyal koronoid prosesi üzerine aşırı yük binmesine neden olan bu hastalık bölgede kırık, çatlak, kondral doku hasarlarının altında yatan temel sebep sayılır (8).

Radius ve ulnanın distal epifiz hatlarının birlikte kapanması ise immature köpeklerde görülebilmekte ve ciddi ekstremite kısalığı ile birlikte angular ve rotasyonel deformitelere neden olabilmektedir $(1,5)$.

Büyüme deformiteleri operatif olarak, oluşan probleme, angulasyon ve rotasyonun derecesine ve etkilenen hayvanın gelişimini ne derece tamamladığına bağlı olarak tek başına yapılan dinamik ostektomi veya korrektif osteotomi sonrası intrameduller pin, plak veya eksternal fiksatör uygulamaları ile sağaltılmaktadır $(1,5,6,7)$.

$\mathrm{Bu}$ çalışma ile distal ve proksimal büyüme plaklarının erken kapanmasına bağlı olarak oluşan radius kısalığ 1 sonucu meydane gelen kısa radius sendromunun elastik eksternal fiksatör ile sağaltımının klinik ve radyolojik sonuçlarının paylaşılması amaçlanmıştır.

\section{Olgu Tanımı}

$\mathrm{Bu}$ çalışmanın konusunu Ankara Üniversitesi Veteriner Fakültesi Hayvan Hastanesi Cerrahi Kliniği’ne ön ekstremitede topallık şikâyeti ile getirilen biri 4 diğeri 5 aylık yaştaki sırası ile mix ve alman çoban köpeği ırklarındaki 2 erkek köpek oluşturdu.

Yapılan klinik ve radyolojik muayeneler sonucu olgularda radiusun proksimal ve distal büyüme plaklarının erken kapanmasına bağlı olarak radius kısalığı şekillendiği ve bunun kaput radiinin distale luksasyonu ve humeroradial eklemde uyumsuzluğa sebep olduğu belirlendi ve kısa radius sendromu teşhisi konuldu (Şekil 1, Şekil 2).

Olgulara radius'un proksimal 1/3'ünün distaline $2 \mathrm{~cm}$ 'lik blok ostektomi uygulandı (Şekil 3). Proksimal radiusun distaline ve olekranona transversal olarak latero-medial yönde 2,0 mm kalınlığında iki adet Steinmann pin uygulandı. Pinlerin hem mediyal uçlarını hem de lateral uçlarını birbirine doğru çekmesini sağlamak amacıyla elastik bantlar yerleştirilerek eksternal skeletal fiksatör sistemi kuruldu (Şekil 4, Şekil 5). Distraksiyonun devam ettiği süreçte PVC destekli bandaj ile hastaların ekstremitesine yüklenmesi önlendi. Bu uygulamaya eklemde oluşan uyumsuzluk 
ortadan kaybolana kadar devam edildi. Olguların iyileşme süreci, klinik ve radyografik olarak 10 günlük periyotlarda değerlendirildi.
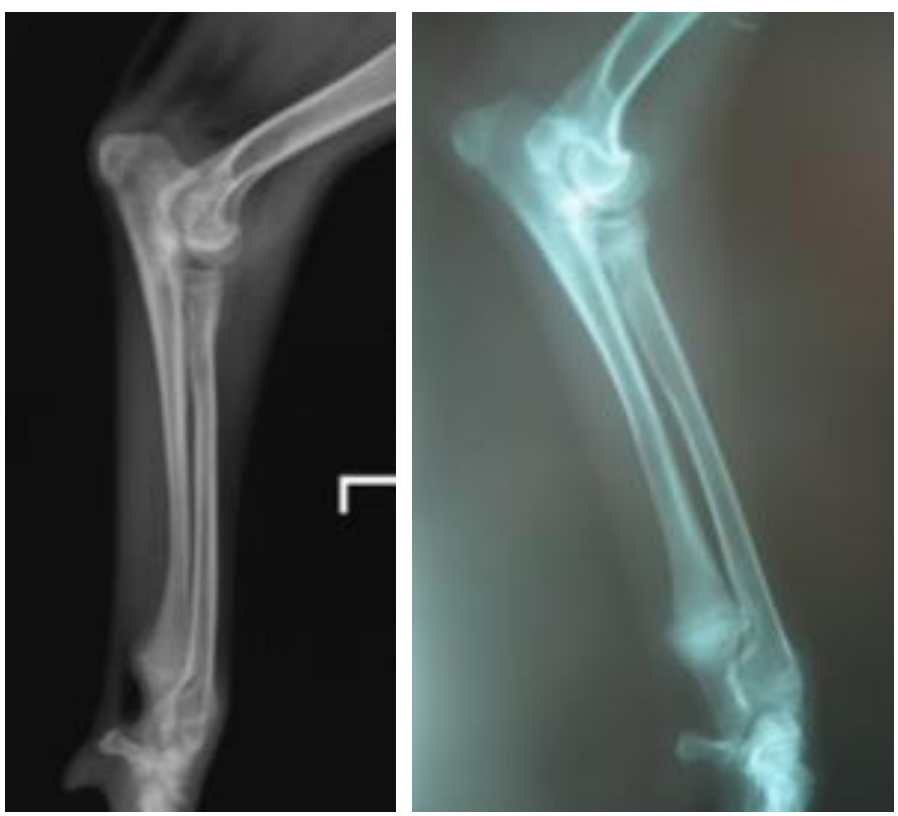

Şekil 1: Olgu 1 (sol) ve olgu 2 (sağ) hastalara ait mediyo lateral radyografiler, kısa redius sendromuna bağl1 dirsek uyumsuzluğu.

Figure 1: Case 1 (left) and 2 (right) medio lateral radiographies, elbow incoungrity due to short radius syndrome

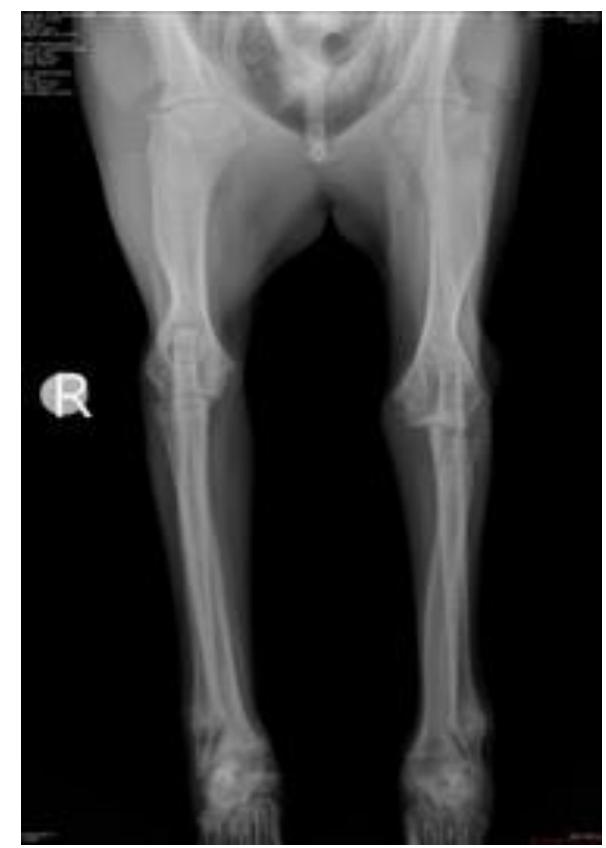

Şekil 2: Olgu 1' e ait kraniyo kaudal görünümde dirsek uyumsuzluğu.

Figure 2: Radiography of case 1, cranio caudal view of elbow incoungrity. 


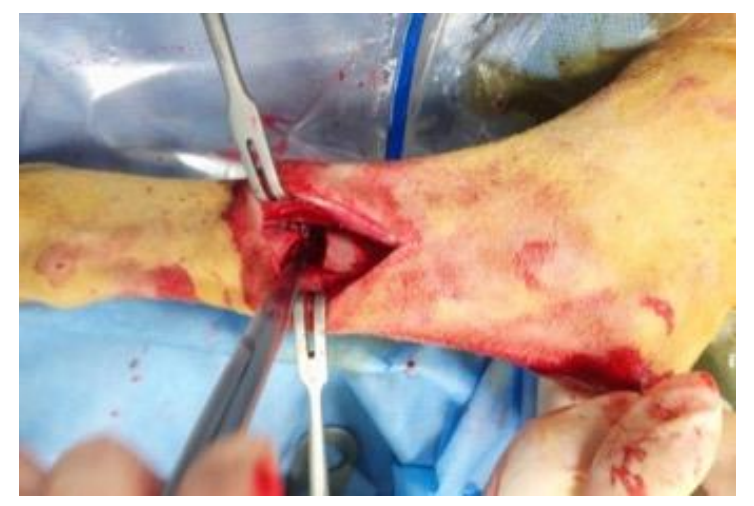

Şekil 3: Radius'un proksimal 1/3'ünün distaline uygulanan $2 \mathrm{~cm}$ 'lik blok ostektominin intraoperatif görüntüsü.

Figure 3: Intra operative picture of $2 \mathrm{~cm}$ block resection to the end of proximal 1/3 of radius.
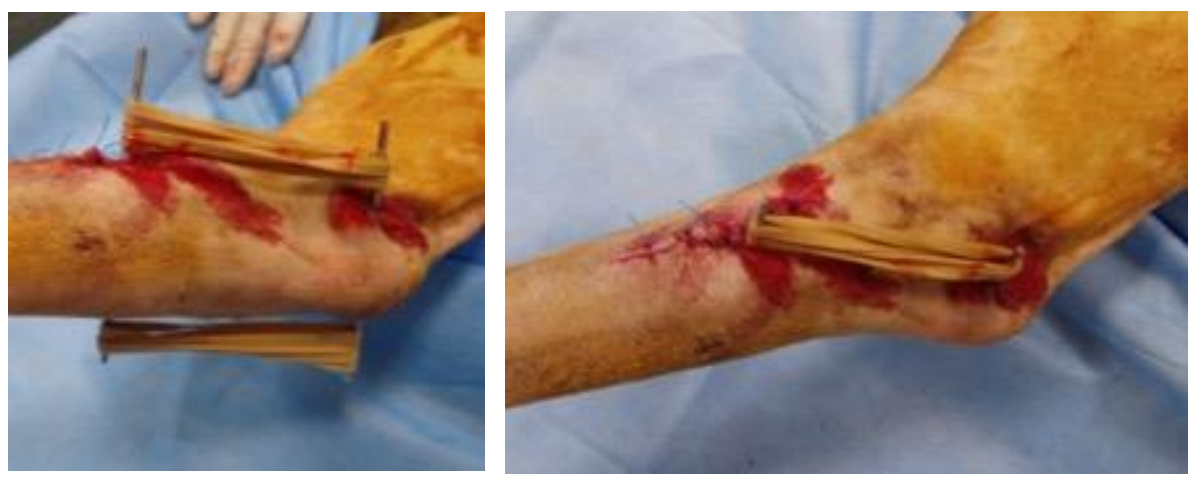

Şekil 4: Olgu 1'e ait intraoperatif elastik eksternal fiksatör görüntüsü.

Figure 4: Elastic external fixation in case 1.
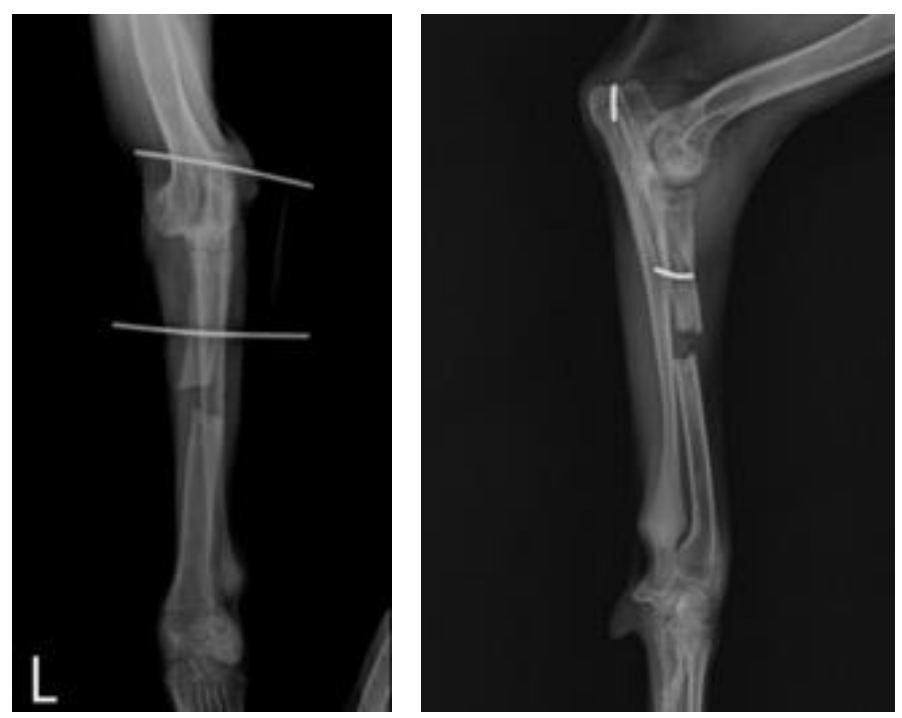

Şekil 5: Olgu 1'e ait postoperatif kraniyo kaudal (sol) ve mediyo lateral (sağ) radiografik görüntüleri.

Figure 5: Post operative cranio caudal radiography of case 1 (left) and medio lateral (right) radiography. 

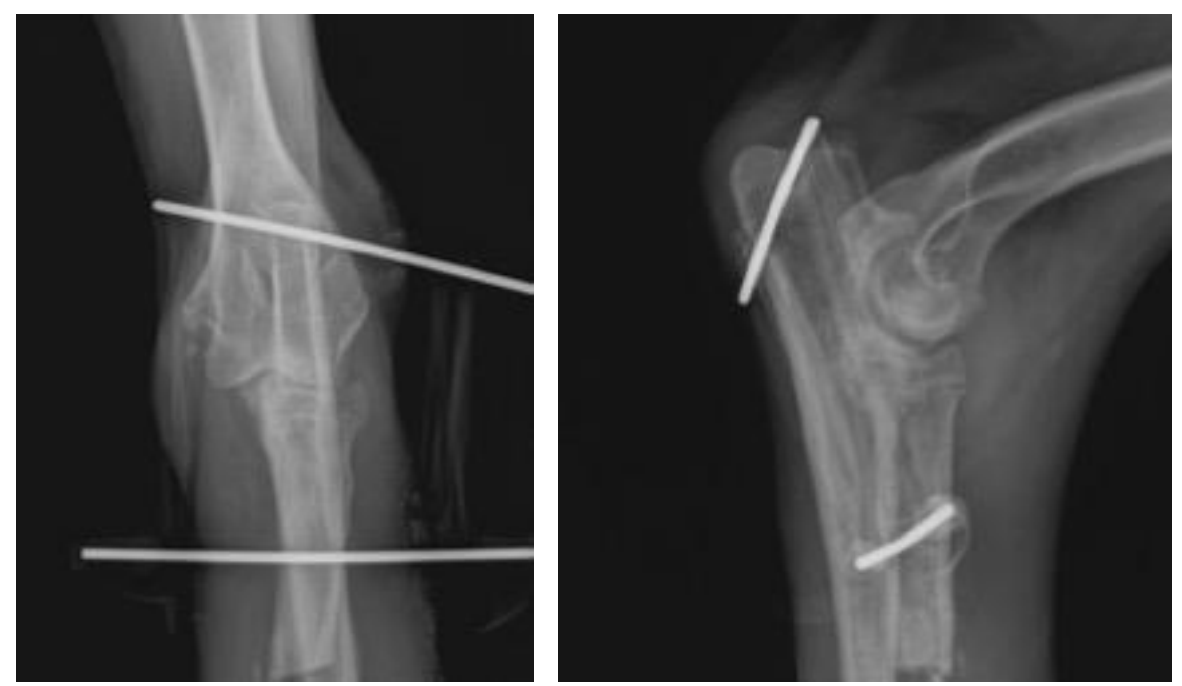

Şekil 6: Olgu 1 Postoperatif 10. gün radyografik muayenesinde gözlenen dirsek uyumsuzluğundaki azalma.

Figure 6: Decraesed elbow incoungrity in case 1, post operative 10th day.

Onuncu günün sonunda yapılan radyografik kontrollerde eklem uyumsuzluğunun ortadan kalktığ1 ve ostektomi hattını kallus dokusunun oluşmaya başladığı saptandı (Şekil 6). Yirminci günün sonunda ise eklem uyumsuzluğunun kaybolduğu ve ostektomi hattının kallus dokusu ile dolduğu belirlendi ve fiksatörler uzaklaştırıldı. Tam kaynama sağlanana kadar hasta kontrollere çağırıldı. Son kontrollerde radius kaynamış ve uyumsuzluğun ortadan kalktığı ve hastanın ilgili ekstremiteye yük bindirmeye başladığı görüldü.

\section{Tartışma ve Sonuç}

Yapılan literatür çalışması elastik eksternal fiksatör uygulamasının art. kübiti luksasyonu, kısa radius sağaltımında ve ulna kısalığına bağlı radiusta valgus deformitesi tespit edilen olgularda kullanıldığını gösterdi $(6,9)$. Yapılan çalışmalarda olgular; ulna, radius ve humerusun farklı yerlerine yerleştirilen pinlerle uygulanan elastik eksternal fiksatörlerle sağaltıldığı ve 8-10 günlük süre içerisinde olumlu sonuçlar alındığı, tekniğin ise hızlı ve kolay uygulanabilir olması yanında ucuz olması ile başarılı olduğu bildirildi.

Guthrie ve arkadaşları zaman zaman bu yöntemde proksimal ulna ve radiusu birbirine bir vida ile sabitlemek gerektiğini bildirse de bizim hastalarımızda böyle bir uygulamaya gerek kalmadı (3).

Yaptığımız çalışmada ise 10. gün konrolde humeroradial eklem boşluğunun kapanması ve 20. gün kontrolde eklem uyumsuzluğunun ortadan kalkması literatür verileri ile paralellik gösterdi ve teknik, erken epifizer kapanmaya bağlı kısa radius sendromunun sağaltımında başarılı olarak bulundu.

\section{Kaynaklar}

1. Carrig CB (1983): Growth abnormalities of the canine radius and ulna. Veterinary Clinics of North America: Small Animal Practise, 13(1), 91-115.

2. Cook CR, and Cook JL (2009): Diagnostic imaging of canine elbow dysplasia: A Review. Veterinary Surgery 38 , 144-153.

3. Guthrie S, Pead M (1992): A complication arising after surgical correction of short radius syndrome. J Small Anim Pract 33, 24-26

4. Hazewinkel HAW (1989): Nutrition in relation to skeletal growth deformities. J Small Anim Pract 30, 625-630.

5. Johnson AL (1992): Treatment of growth deformities with external skeletal fixation. Veterinary Clinics of North 
America: Small Animal Practise, 22(1), 209-223.

6. Mason TA, Baker MJ (1978): The surgical management of elbow joint deformity associated with premature growth plate closure in dogs. J Small Anim Pract. 19, 639-645.

7. Preston CA, Schulz KS, Taylor KT, Kass PH, Hagan CE, Stover SM (2001): In vitro experimental study of the effect of radial shortening and ulnar ostectomy on contact patterns in the elbow joint of dogs. Am J Vet Res 62, $1548-1556$.

8. Temwichitr J, Leegwater PAJ, Hazewinkel HAW (2010): Fragmented coronoid process in the dog: A heritable disease. Vet J, 185, 123-129.

9. Vedrine B (2017): Use of an elastic transarticular external fixator construct for immobilization of the elbow joint. Can Vet J, 58, 353-359. 